\title{
OBTENÇÃO E CARACTERIZAÇÃO DE MATERIAL DE REFERÊNCIA EM BLENDS DE COFFEA. ARABICA E C. CANEPHORA
}

\section{Cinthia de Carvalho Couto ${ }^{1}$; Alexandra Mara Goulart Nunes Mamede ${ }^{2}$; Melicia Cintia Galdeano $^{3}$; Edna Maria Morais Oliveira ${ }^{3}$; Otniel Freitas-Silva ${ }^{3}$}

1 Departamento de Tecnologia dos Alimentos - Universidade Federal do Estado do Rio de Janeiro - CEP: 22290-180 - Rio de Janeiro - RJ - Brasil, Telefone: +55 (21) 2542-7276 - e-mail: (cinthiaccouto@ gmail.com)

2 Bolsista Consórcio Pesquisa Café, DSc - CEP: 23020-470 - Rio de Janeiro - RJ - Brasil.

3 Embrapa Agroindústria de Alimentos - CEP: 23020-470 - Rio de Janeiro - RJ - Brasil.

Não há no Brasil uma legislação para características mínimas de qualidade e autenticidade para blends de Coffea arabica e C. canephora robusta torrados e moídos. A fim de obter padrão de identidade para rotulagem, faz-se necessária a elaboração de material de referência (MR) que permita a identificação e ratificação da composição percentual dos blends de café, para dar suporte a uma possível legislação. Atualmente os MR disponíveis para comercialização que utilizam o café como matriz, foram desenvolvidos para identificação de alguns analitos, tais como, ocratoxina A, cafeína, acrilamida, entre outros. No entanto, ainda não existe nenhum MR de C. arabica e C. canephora para verificação dos teores dessas espécies nos blends. O objetivo do trabalho foi elaborar e caracterizar um candidato a MR de $C$. arabica, C. canephora e mesclas das duas espécies. O café verde foi torrado a $240{ }^{\circ} \mathrm{C}$ por 14 minutos, moído e peneirado na granulometria < $600 \mu \mathrm{m}$. O MR consistiu dos percentuais: 100:0; 95:5; 75:25; 50:50, 25:75, 5:95 e 0:100 de C. arabica e C. canephora, respectivamente. Foram avaliados a perda de massa durante a torra, a cor instrumental, o tamanho e a distribuição de partículas por difratometria laser. Os resultados indicaram que o MR apresentou homogeneidade quanto ao tamanho e a distribuição de partícula e perda de massa. A análise de cor instrumental mostrou maior luminosidade para espécie C. canephora comparado ao C. arabica, segundo o parâmetro CIEL*. O MR apresentou tendência ao amarelo conforme aumentava a proporção de C. canephora no blend, de acordo com o parâmetro CIEb* e o ângulo Hue, e uma tendência a tonalidade vermelha, segundo os valores de CIEa*. Concluiu-se que as condições estabelecidas para a produção do MR de blend de café apresentou uniformidade e homogeneidade adequadas e podem ser utilizadas como parâmetro para novos MR que utilizam café torrado e moído, bem como contribuir para avaliação da garantia de qualidade e identidade do produto e para fins de rotulagem onde constem os percentuais de $C$. arabica e C. canephora no blend.

Palavras-chave: Café comercial; material de referência; rotulagem. 